\title{
Fragmentation of Peptide Disulfides under Conditions of Negative Ion Mass Spectrometry: Studies of Oxidized Glutathione and Contryphan
}

\author{
Suman S. Thakur and Padmanabhan Balaram \\ Molecular Biophysics Unit, Indian Institute of Science, Bangalore, India
}

The fragmentation of positive and negative ions of peptide disulfides under mass spectrometric conditions yields distinctly different product ion distributions. A negative ion upon collision induced dissociation yields intense product ions, which correspond to cleavage at the disulfide linkage. The complete assignment of the product ions obtained upon fragmentation of oxidized glutathione in an ion trap is presented. The cleavage at the disulfide site is mediated by abstraction of $\mathrm{C}^{\alpha} \mathrm{H}$ and $\mathrm{C}^{\beta} \mathrm{H}$ protons resulting in product ions derived by neutral loss of $\mathrm{H}_{2} \mathrm{~S}_{2}$ and $\mathrm{H}_{2} \mathrm{~S}$. The formation of peptide thioaldehydes and persulfides at the cysteine sites is established. Dehydroalanine formation at the Cys residue is predominant. The case of a contryphan, a cyclic peptide disulfide derived from Conus snail venom, illustrates the utility of negative ion mass spectrometry in disulfide identification. Complementary information is derived by combining the fragmentation patterns obtained from positive and negative ions of disulfide containing peptides. (J Am Soc Mass Spectrom 2008, 19, 358-366) (c) 2008 American Society for Mass Spectrometry

$\mathrm{M}$ ass spectrometric characterization of disulfide bonded peptides is generally achieved by the reduction of the S-S bond followed by alkylation [1-4] or by oxidation to sulfonic acid derivatives [5]. Subsequent gas-phase fragmentation results in readily identifiable backbone cleavage products. Several groups have focused on the mass spectrometric analysis of peptides containing intact disulfide bonds using both positive and negative ions for gas-phase fragmentation [6-12]. In the case of positively charged peptide ions, disulfide bond fragmentation occurs with much lower efficiency than cleavage of backbone peptide bonds, under conditions of collision induced dissociation with non-mobile protons suggested to play an important role [11]. Restricted proton mobility along the polypeptide backbone has also been implicated in cases of disulfide cleavages in polypeptides, which have been cationized using gold (I) [7]. The use of metal ions as gas-phase disulfide cleavage agents has also been investigated [12]. In general, only limited information regarding structure can be derived from intact disulfide peptides in the positive ion mode. In contrast, several recent studies have emphasized the utility of negative ion mass spectrometry [7, 10, 13-18]. Specifically, Bowie and coworkers have presented assignments of product ion spectra obtained by negative ion

Address reprint requests to Dr. P. Balaram, Molecular Biophysics Unit, Indian Institute of Science, Bangalore 560012, India. E-mail: pb@mbu.iisc. ernet.in electrospray mass spectrometry of peptides containing both intra and inter molecular disulfide bond [10, 18]. The present study complements the work of Bowie and coworkers and further provides mechanistic details by examining second generation product ions by using ion trap mass spectrometry.

In the structural analysis of peptides containing intact disulfides, under negative ion conditions, proton abstraction from the $\mathrm{C}^{\alpha} \mathrm{H}$ and $\mathrm{C}^{\beta} \mathrm{H}$ positions of the $\mathrm{Cys}$ residue results in diverse fragmentation reactions, leading to cleavage of disulfide linkages. In the case of peptides that contain labile peptide bonds, for example X-Pro sequences, preferential cleavage at these sites results in two linear chains linked by a disulfide bond, which then undergo further fragmentation at the disulfide linkage. The utility of such a linearization process, which results in unsymmetrical cystine peptides, has been demonstrated in the sequence analysis of the contryphans from crude Conus venom mixtures [19].

To establish the multiple modes of fragmentation at disulfide linkages under conditions of negative ion mass spectrometry, we carried out studies on oxidized glutathione and attempted to identify the entire range of product ions observed. The results established that $\alpha$ and $\beta$ elimination processes can lead to persulfides, thioaldehydes, and dehydroalanine residues at the Cys position. Neutral losses of $\mathrm{H}_{2} \mathrm{~S}_{2}$ and $\mathrm{H}_{2} \mathrm{~S}$ from the precursor ions result in a spectrum of product ions. 


\section{Experimental}

\section{Materials}

Oxidized glutathione was obtained from Sigma (St. Louis, MO). Cone snail samples were collected by Professor K. S. Krishnan and collaborators from the southeastern coast of India. Crude venom samples were obtained by dissecting the venom duct and extracting the total peptide mixture into alcohol solution [4, 19]. Electrospray ionization (ESI) mass spectrometry studies were carried out on HPLC purified peptide fraction and also on crude venom mixtures using an on-line HPLC.

\section{Mass Spectrometry}

LC-ESI-MS were recorded in positive/negative ion mode using an Esquire 3000-plus mass spectrometer (Bruker Daltonics, Bremen, Germany) consisting of two octopoles followed by an ion trap. The extract was dissolved in water Milli Q (Millipore, France) and run through a Phenomenex $\mathrm{C}_{18}$ column $(4.6 \mathrm{~mm} \times 50 \mathrm{~mm}, 4 \mu \mathrm{m}$ particle size, 90 Å pore size) (Phenomenex, California, USA) using acetonitrile/water/0.1\% formic acid $\left(\mathrm{CH}_{3} \mathrm{CN} / \mathrm{H}_{2} \mathrm{O} / 0.1 \%\right.$ $\mathrm{HCOOH})$ in the positive ion mode. Negative ion mode spectra were recorded using acetonitrile/water/ammonium acetate $\left(\mathrm{CH}_{3} \mathrm{CN} / \mathrm{H}_{2} \mathrm{O} / \mathrm{NH}_{4} \mathrm{COOCH}_{3}\right)$ as the eluting solvent. The flow rate was maintained at $0.2 \mathrm{~mL}$ $\mathrm{min}^{-1}$, with detection at $226 \mathrm{~nm}$. Helium was used as the collision gas for collision induced dissociation (CID) experiments. The data were processed using Esquire data analysis software, version 3.1 (Bruker Daltonics, Bremen, Germany).

ESI-MS (direct injection) spectra were also obtained in positive/negative ion mode by direct injection of purified samples into the system using a syringe pump (ColeParmer, Vernon Hills, IL) operated at a flow rate of 200 to $240 \mu \mathrm{L} \mathrm{h}^{-1}$. Deuterium exchange of oxidized glutathione has been done by dissolving in deuterated water $\left(\mathrm{D}_{2} \mathrm{O}\right)$. Positive ion mode spectra were recorded in $\mathrm{D}_{2} \mathrm{O}$ and $0.1 \%$ deuterated acetic acid $\left(\mathrm{CD}_{3} \mathrm{COOD}\right)$. Negative ion mode spectra were recorded using $\mathrm{D}_{2} \mathrm{O}$ and $1 \mathrm{mM}$ deuterated ammonium acetate, prepared by lyophilizing $\mathrm{CH}_{3} \mathrm{COONH}_{4}$ from $\mathrm{D}_{2} \mathrm{O}$.

\section{Results and Discussion}

\section{Oxidized Glutathione}

Figure 1a shows the ESI-MS/MS spectrum obtained from fragmentation of the parent oxidized glutathione ( $\gamma$-glutamyl-cysteinyl-glycine, ${ }^{\gamma} \mathrm{E}-\mathrm{C}-\mathrm{G}, \mathrm{M}=612.6 \mathrm{Da}$ ) in negative ion mode. Collision induced dissociation (CID) in an ion trap of the $[\mathrm{M}-\mathrm{H}]^{-}$species $(m / z 611.5)$ results in intense product ions with $\mathrm{m} / \mathrm{z}$ values of 593.0, 482.0, 337.9 , and 305.9. The ions below $\mathrm{m} / \mathrm{z} 400$ correspond to the species obtained from fragmentation at the disulfide bond. The intense ion at $\mathrm{m} / \mathrm{z} 482.0$ may be assigned to the species obtained by the loss of one N-terminal, $\gamma$-glutamyl residue from the symmetrical cystine peptide. The loss of 129 Da may be rationalized by the elimination of a neutral pyroglutamic acid fragment
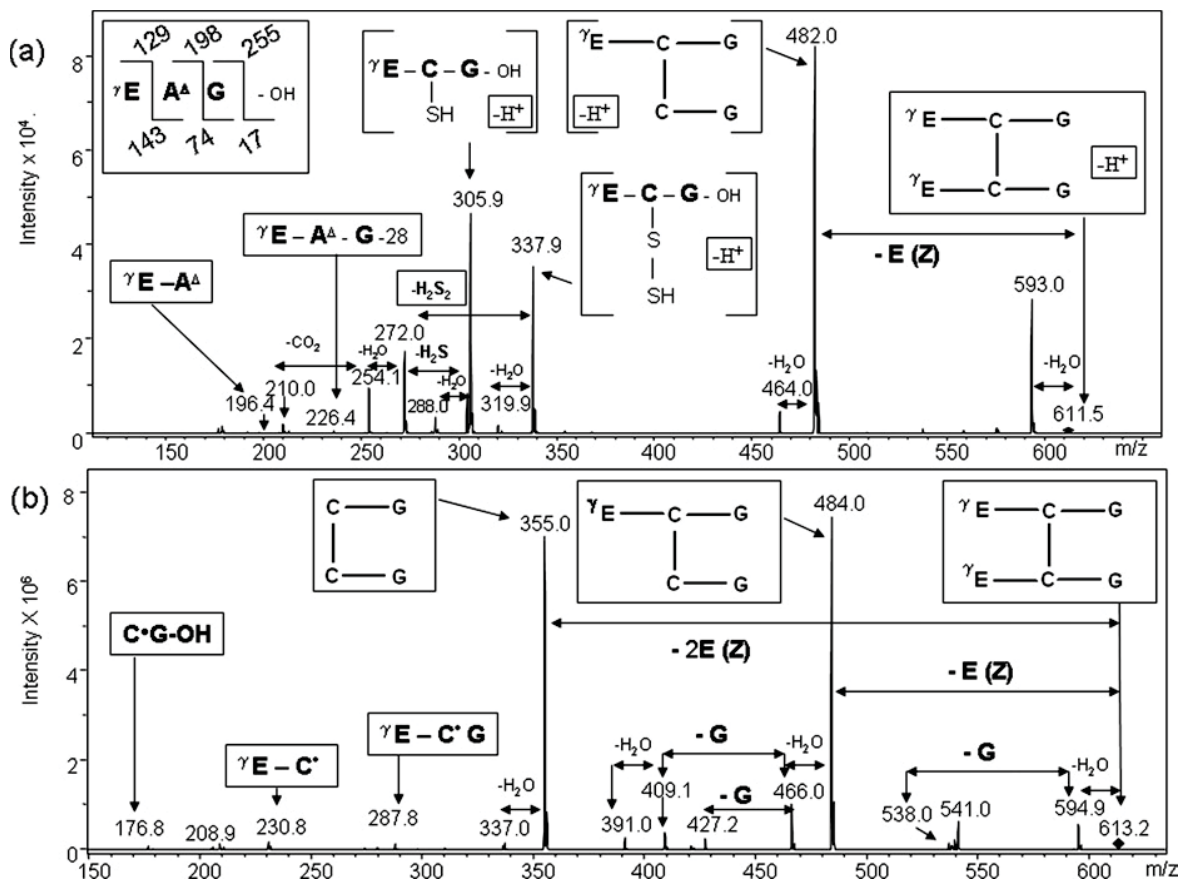

Figure 1. (a) LC-ESI-MS/MS $\left(\mathrm{MS}_{2}\right)$ of oxidized glutathione $(611.5 \mathrm{~m} / \mathrm{z})$ in negative ion mode. The peaks at $m / z 305.9$ and 337.9 are shown as deprotonated tripeptide persulfide. ${ }^{\gamma} \mathrm{E}$ ( $\gamma$-glutamyl): $129 \mathrm{Da}$, $\mathrm{A}^{\Delta}$ (dehydroalanine): $69 \mathrm{Da}, \mathrm{C}$ (cysteine): $103 \mathrm{Da}$. (b) LC-ESI-MS/MS of oxidized glutathione $(613.2 \mathrm{~m} / \mathrm{z})$ in positive ion mode ${ }^{\gamma} \mathrm{E}$ ( $\gamma$-glutamyl): $129 \mathrm{Da}, \mathrm{C}^{\cdot}$ (cysteine thioaldehyde): $101 \mathrm{Da}, \mathrm{C}$ (cysteine): $103 \mathrm{Da}$. 


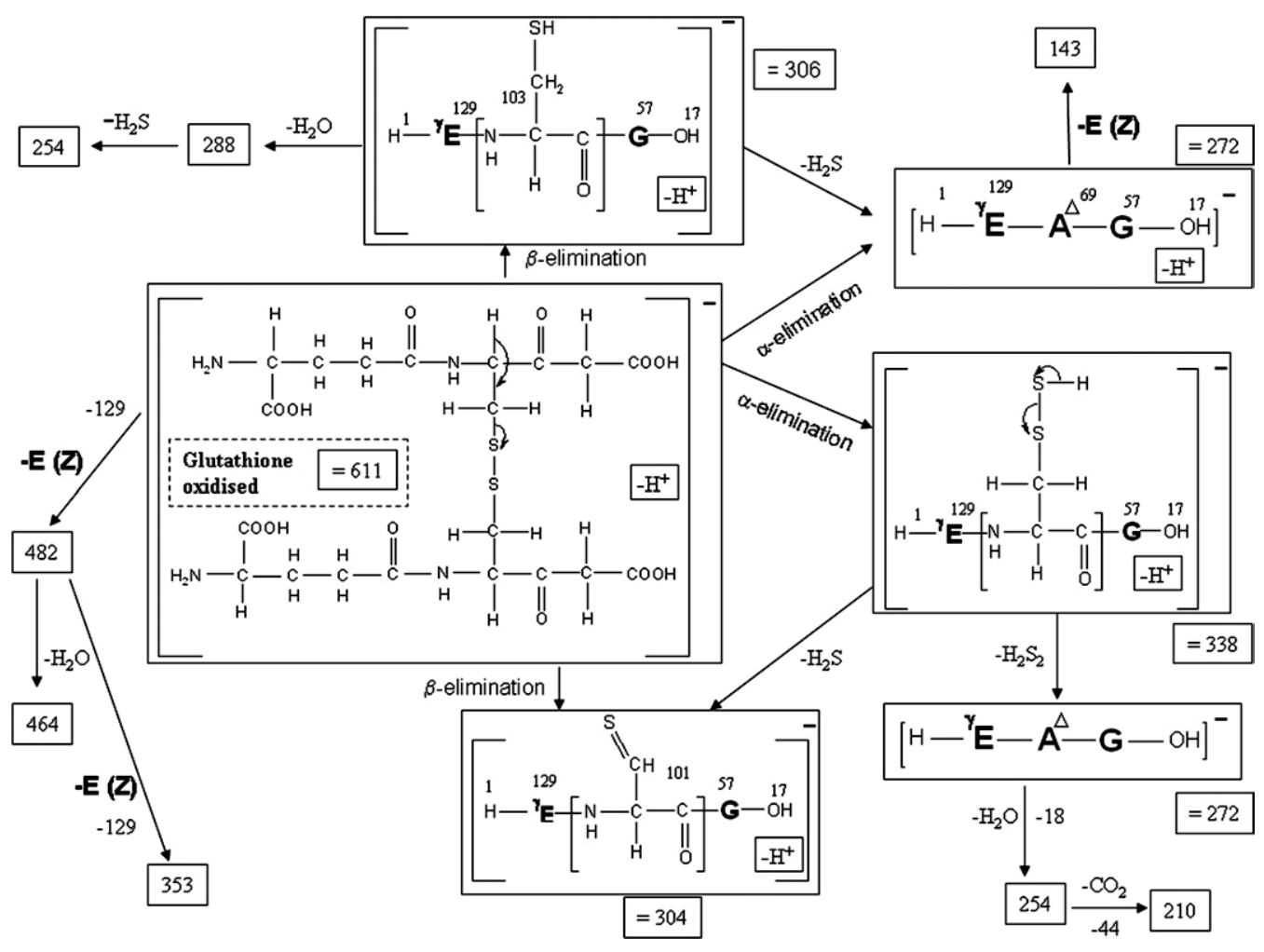

Scheme 1. A summary of the modes of fragmentation of the negative ion derived from oxidized glutathione.

[indicated in Figure 1a and Scheme 1 as $-E(Z)$ ], formed by the nucleophilic attack of the terminal amino group on the carbonyl group of the $\gamma$-glutamyl peptide bond.

Figure $1 \mathrm{~b}$ illustrates the fragmentation pattern obtained from the positive ion of oxidized glutathione $[\mathrm{M}+\mathrm{H}]^{+}=613.2$. The dramatic difference between the spectra under negative and positive ion conditions is evident. Indeed, only two intense peaks are observed at $\mathrm{m} / \mathrm{z} 484.0$ and 355.0 from the fragmentation of the [M + $\mathrm{H}]^{+}$species. Neither of these peaks corresponds to a disulfide cleaved product. The product ion at $\mathrm{m} / \mathrm{z} 484.0$ arises by loss of a glutamyl residue $(-129 \mathrm{Da})$, while $\mathrm{m} / \mathrm{z} 355.0$ results from the loss of two glutamyl residues leaving the dipeptide Cys-Gly fragments covalently linked via a disulfide bridge. In sharp contrast, a negative ion spectrum provides several ions, which are formed by cleavage of the disulfide bridge.

Scheme 1 provides a summary of the possible cleavage modes and resultant product ions obtained from mass spectrometric fragmentation of the negative ion of oxidized glutathione. Interestingly, two intense peaks at $\mathrm{m} / \mathrm{z} 305.9$ and 337.9 arise due to the initial cleavage that results in the formation of an RSSH moiety. An $\alpha$-elimination process results in the formation of dehydroalanine at one Cys position and a persulfide at the other, resulting in peaks with $\mathrm{m} / \mathrm{z}$ values of 272 and 338 . Elimination of a proton from the $\beta$ position results in the formation of cysteine (reduced thiol) at one Cys position and the thioaldehyde at the other. This gives rise to peaks at $\mathrm{m} / \mathrm{z} 305.8$ and 303.9. Confirmation of the assignment is obtained by the further fragmentation $\left(\mathrm{MS}_{3}\right)$ of the ion observed at $\mathrm{m} / \mathrm{z} 482.0$ (Figure 2). Subsequent neutral loss of $\mathrm{H}_{2} \mathrm{~S}_{2}$ and $\mathrm{H}_{2} \mathrm{~S}$ can occur from the persulfide species with $\mathrm{m} / \mathrm{z}$ value of 338 . This is confirmed by an $\mathrm{MS}_{3}$ experiment carried out with the product ion at $\mathrm{m} / \mathrm{z} 338$ (Figure 3). Loss of $\mathrm{H}_{2} \mathrm{~S}$ from the thiol species at $m / z 305.8$ also gives rise to the product ion at $m / z 272$, as confirmed by an $\mathrm{MS}_{4}$ experiment (Figure 4). The product ions that result from peptide bond cleavage, and those containing the dehydroalanine residue (Dha, $\mathrm{A}^{\Delta}$ ) are readily assigned.

Scheme 2 rationalizes the formation of the product ions derived by fragmentation of oxidized glutathione at the disulfide bridge. The product ion distributions will, of course, be more complex in the case of unsymmetrical cystine peptides, in which the two linked peptide chains have different sequences. We illustrate below an example of such a situation that is encountered in the fragmentation of a cyclic peptide disulfide, contryphan, in which the initial backbone cleavage generates unsymmetrical precursor ions.

\section{Contryphan}

Contryphans are a group of single disulfide bond containing peptides obtained from the venom of predatory cone snails $[4,20]$. We have recently described the fragmentation of the intact disulfide bonded peptide under conditions of positive ion mass spectrometry in an attempt to directly sequence 


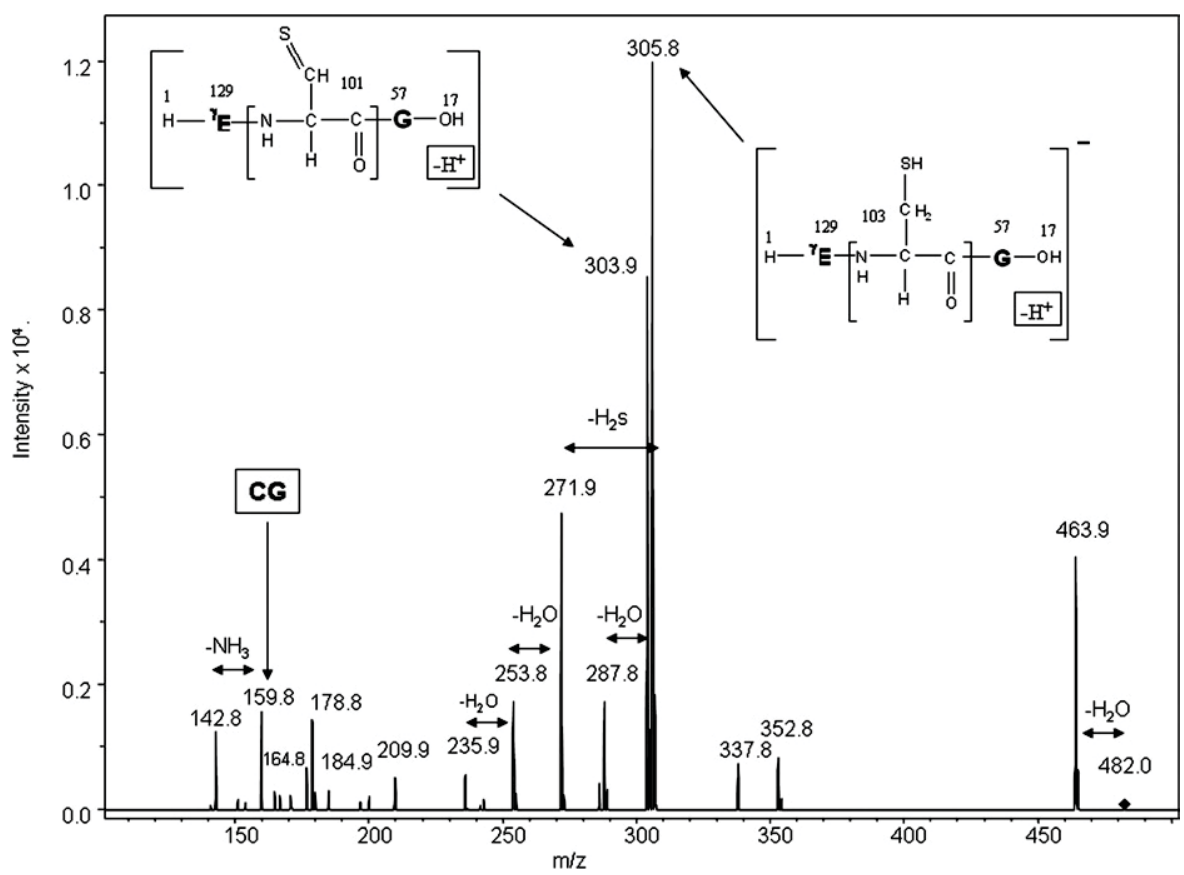

Figure 2. Fragmentation pattern obtained in collision induced dissociation of the negative ion at $\mathrm{m} / \mathrm{z}$ 482.0 derived from the negative ion of oxidized glutathione $(611.5 \mathrm{~m} / \mathrm{z})$.

peptides from natural mixtures. Product ions are derived from an initial precursor ion, which arises from the fragmentation of one of the labile peptide bonds in the sequence, predominantly the tertiary amide bonds preceding proline (Pro) or hydroxyproline (Hyp) residues, resulting in the formation of unsymmetrical linearized cystine peptide sequences. Subsequent cleavages of the disulfide bonds holding two linked peptide chains are observed [19].

Under the conditions of negative ion mass spectrometry, preferential cleavage at the disulfide bond may be anticipated, since both $\alpha$ and $\beta$ elimination reactions at

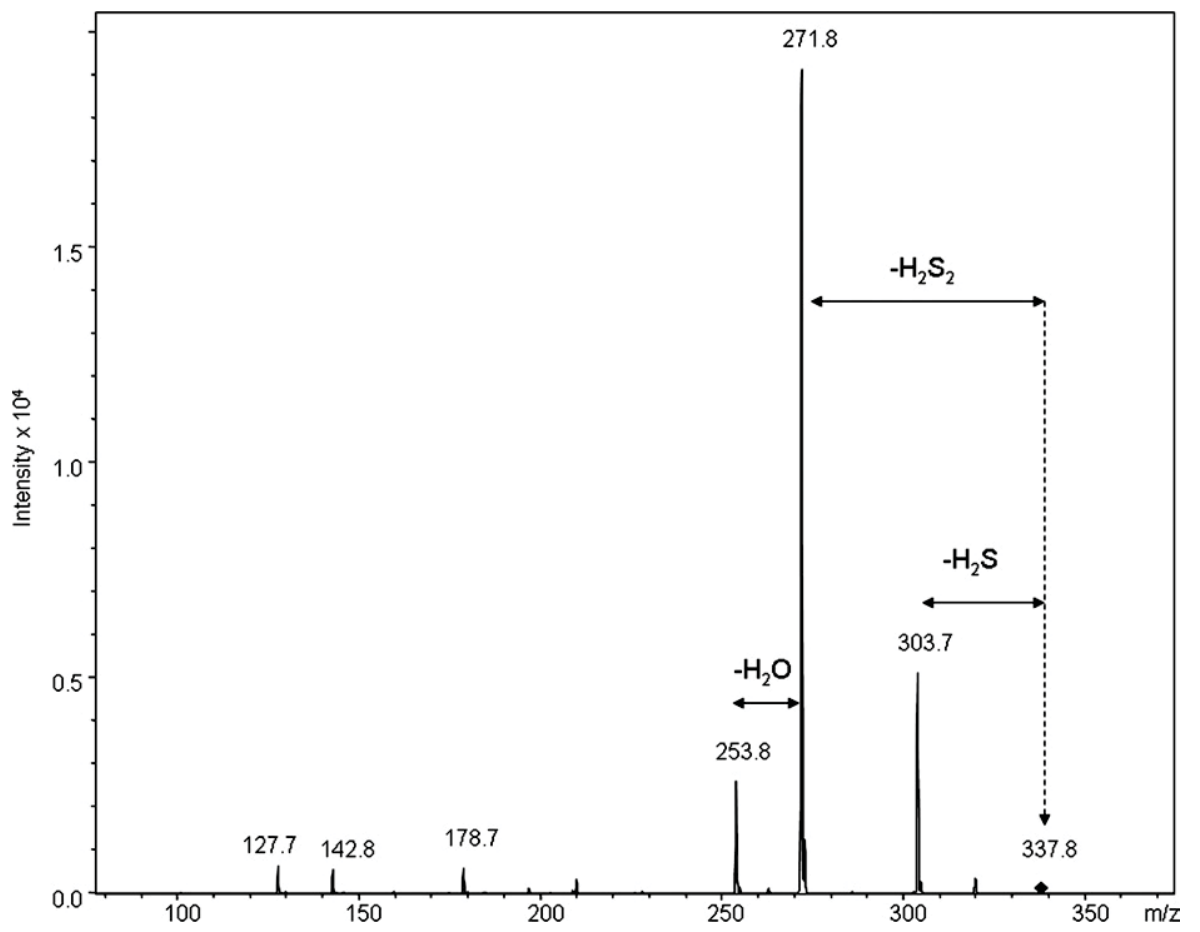

Figure 3. Fragmentation pattern $\left(\mathrm{MS}_{3}\right)$ obtained in collision induced dissociation of the negative ion at $\mathrm{m} / \mathrm{z} 337.9$ derived from the negative ion of oxidized glutathione $(611.5 \mathrm{~m} / \mathrm{z})$. 


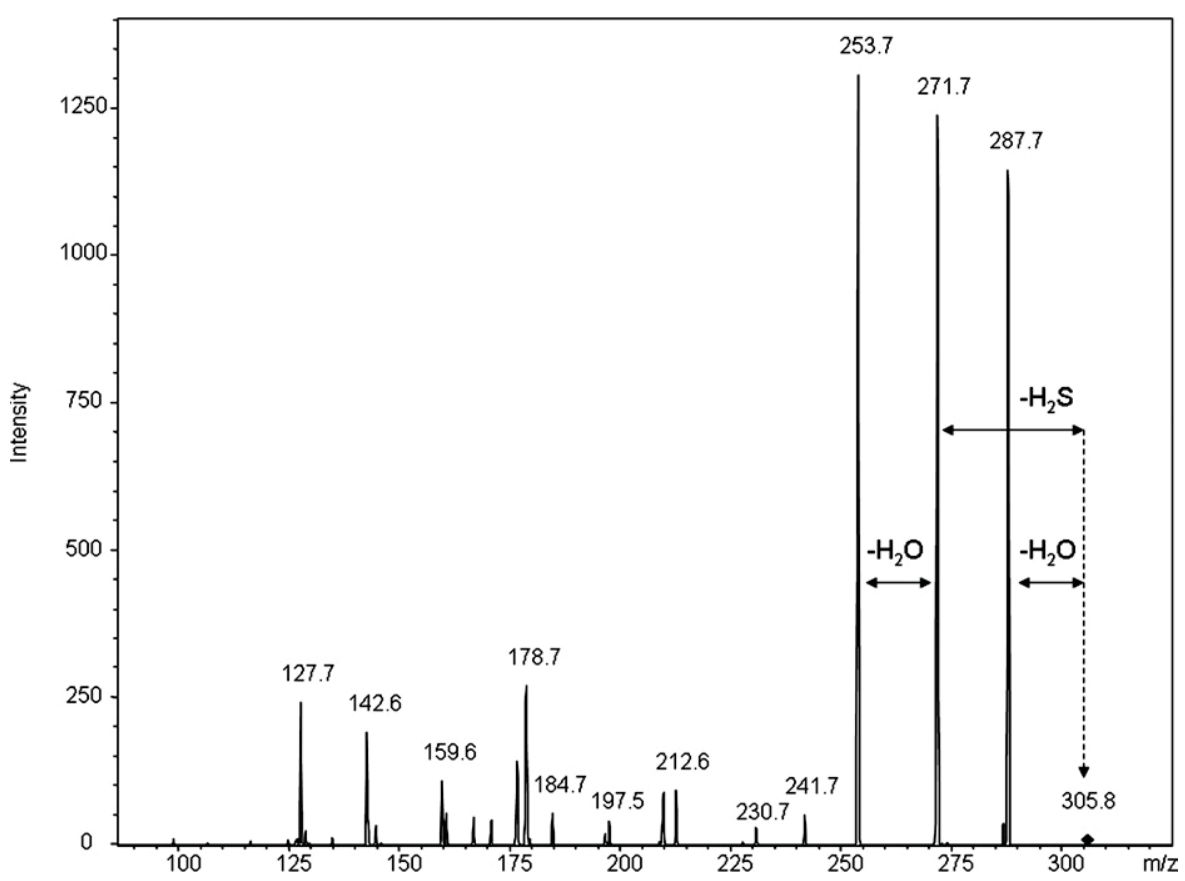

Figure 4. Fragmentation pattern $\left(\mathrm{MS}_{4}\right)$ obtained in collision induced dissociation of the negative ion at $\mathrm{m} / \mathrm{z} 305.8$ derived from the ion at $\mathrm{m} / \mathrm{z} 482.0$ obtained from the negative ion of oxidized glutathione $(611.5 \mathrm{~m} / \mathrm{z})$.

the cystine bridge are likely to be facile. These peptides have the general sequence:

C P/O ${ }^{\mathrm{D}} \mathrm{W} /{ }^{\mathrm{D}} \mathrm{L} \mathrm{D} \mathrm{P} W \mathrm{C}-\mathrm{NH}_{2} / \mathrm{OH},(\mathrm{O}=$ 4-hydroxyproline, Hyp, $\left.{ }^{\mathrm{D}} \mathrm{W}=\mathrm{D}-\operatorname{Trp},{ }^{\mathrm{D}} \mathrm{L}=\mathrm{D}-\mathrm{Leu}\right)$.

Figure $5 \mathrm{a}$ and $\mathrm{b}$ compare the positive and negative ion mass spectra obtained for the contryphan Am 975 from Conus amadis $[4,19]$. Dramatic differences are evident from the distribution of product ions. In the positive ion mode, the intense cleavage products can be rationalized by postulating an initial fragmentation at the X-Pro bond [4, 19, 21, 22]. In the positive ion mode, the single intense peak at $\mathrm{m} / \mathrm{z} 959$ corresponds to loss of $\mathrm{NH}_{3}$ from the C-terminal primary amide group. In the $\mathrm{m} / \mathrm{z}$ range $400-900$, a number of product ions with similar intensities are observed. Peaks in the lower $\mathrm{m} / \mathrm{z}$ region correspond to the product ions in which both the peptide and disulfide bonds have been cleaved.

In sharp contrast, the negative ion mass spectrum reveals intense peaks at $\mathrm{m} / \mathrm{z} 908.3$ and 940.3 , which arise by loss of $\mathrm{H}_{2} \mathrm{~S}(\Delta \mathrm{M}=34)$ and $\mathrm{H}_{2} \mathrm{~S}_{2}(\Delta \mathrm{M}=66)$. Scheme 3 schematically illustrates the modes of fragmentation at the disulfide bridge, which results in the observed fragment ions. It may be noted that both $\alpha$ and $\beta$ elimination reactions lead to linear peptide ions, which differ only in the nature of the modified residues present at the original cysteine positions. Three types of residues arise at the site of disulfide cleavage. (1) Dehydroalanine, $\mathrm{A}^{\Delta}$, residue mass $=69 \mathrm{Da}$; (2) cysteine, $\mathrm{C}$, residue mass $=103 \mathrm{Da}$; (3) $\beta$ thioaldehyde derived by oxidation of the Cys thiol $\left(\mathrm{C}^{*}\right)$, residue mass $=101 \mathrm{Da}$.

The elimination of $\mathrm{H}_{2} \mathrm{~S}_{2}$ results in a product ion containing $\mathrm{A}^{\Delta}$ residues at both cysteine positions. Frag- mentation at the disulfide bond can also take place by the loss of the $\mathrm{C}^{\alpha}$ proton, resulting in the generation of dehydroalanine residue at one position and a persulfide at the other. Subsequent elimination of $\mathrm{H}_{2} \mathrm{~S}$ from the persulfide results in the formation of a thioaldehyde. This mode of disulfide cleavage results in the generation of specific modifications; dehydroalanine: $\left(\mathrm{A}^{\Delta}\right)$ and Cys thioaldehyde ( $\mathrm{C}^{\circ}$ ) at either of the two Cys residues, resulting in pairs of product ion that have the same $\mathrm{m} / \mathrm{z}$ but differ in the nature of the modified residue at the position of the original Cys residue. Inspection of the spectrum in Figure $5 \mathrm{~b}$ reveals two peaks at $\mathrm{m} / \mathrm{z} 940.3$ and 941.2 of nearly equal intensity. The ion at $\mathrm{m} / \mathrm{z} 940.3$ may be assigned to the thioaldehyde $\left(C^{*}\right)$ species. The peak at $m / z 941.2$ presumably corresponds to a radical anion generated by homolytic fission of the persulfide, with corresponding loss of $\mathrm{SH}$ radical resulting in a mass loss of $33 \mathrm{Da}$. The peak at $\mathrm{m} / \mathrm{z} 908.3$ can be unambiguously assigned to the sequence $\mathrm{GA}^{\Delta} \mathrm{OWDPWA}^{\Delta}-$ $\mathrm{NH}_{2}$. Subsequent fragmentation of the negative ion derived from this linearized sequence results in the observed distribution of product ions.

The proposed fragmentation pathways for the formation of dehydroalanine, thioaldehyde, and reduced glutathione are reminiscent of chemical cleavages occurring at the cystine site in the peptide under base catalyzed condition in solutions [23-25]. We have attempted to obtain experimental support for these proton abstraction processes by subjecting a deuterated sample of glutathione, in which all exchangeable hydrogens have been replaced by deuterium, to collision induced dissociation in an ion trap mass spectrometer. 


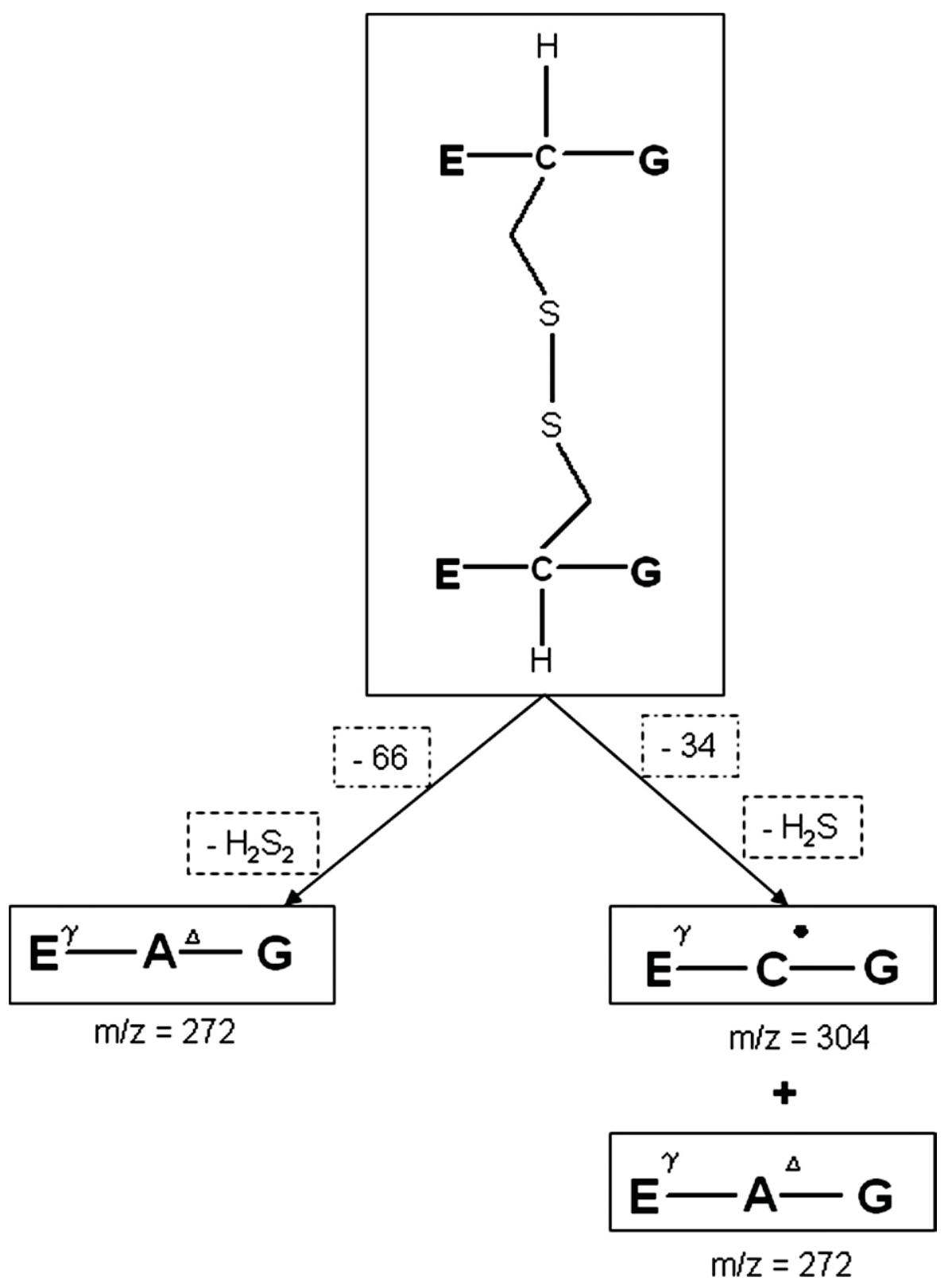

Scheme 2. Summary of the major fragments at the disulfide bridge and the resultant product ions obtained by neutral loss of $\mathrm{H}_{2} \mathrm{~S}_{2}, \mathrm{H}_{2} \mathrm{~S}$, and $\mathrm{S}$ under condition of negative ion mass spectrometry. ${ }^{\gamma} \mathrm{E}$ ( $\gamma$-glutamyl): $129 \mathrm{Da}, \mathrm{A}^{\Delta}$ (dehydroalanine): $69 \mathrm{Da}, \mathrm{C}^{-}$(cysteine thioaldehyde): $101 \mathrm{Da}, \mathrm{C}$ (cysteine): $103 \mathrm{Da}$.

Exhaustive deuteration of oxidized glutathione yields a species in the positive ion mode $[\mathrm{M}+\mathrm{D}]^{+}=626 \mathrm{Da}$ and in negative ion mode $[\mathrm{M}-\mathrm{D}]^{-}=622 \mathrm{Da}$. When the $[\mathrm{M}-\mathrm{D}]^{-}$negative ion is subjected to fragmentation, product ions corresponding to the species ${ }^{\gamma} \mathrm{E}-\mathrm{C}-\mathrm{G}$ (free cysteine) $311.9 \mathrm{~m} / \mathrm{z}$ and ${ }^{\gamma} \mathrm{E}-\mathrm{C}-\mathrm{G}$ (persulfide) $\mathrm{m} / \mathrm{z} 342.9$ are observed in addition to other peaks (Figure 6).

The product ion with $\mathrm{m} / \mathrm{z} 311.9$ arises from the precursor ion $\mathrm{m} / \mathrm{z} 622.1$ by the fragmentation involving a loss of $C^{\beta}$ proton, resulting in the formation of the thioaldehyde and free cysteine. The observation of a major peak at $311.9 \mathrm{~m} / \mathrm{z}$ suggests that six of the seven exchangeable hydrogens in reduced glutathione anion are replaced by deuterium. $\mathrm{M}_{\text {calc }}$ for reduced glutathi- one is $306 \mathrm{Da}$. Since all the exchangeable hydrogens in the precursor ion have been substituted by deuterium, the newly generated species with an additional exchangeable site (thiol group) must be derived from the proton on the carbon backbone, thereby providing experimental support to the mechanism. In contrast, for the product ion corresponding to the persulfide species, two closely spaced peaks are observed at $\mathrm{m} / \mathrm{z} 342.9$ and 343.9. These correspond to a species in which five of the six exchangeable hydrogens are replaced by deuterium $(\mathrm{m} / \mathrm{z}=342.9)$ and a second species, in which all six hydrogens are replaced by deuterium $(\mathrm{m} / \mathrm{z}=343.9)$. Generation of the persulfide species is postulated to proceed by the abstraction of $\mathrm{C}^{x} \mathrm{H}$ proton. The obser- 

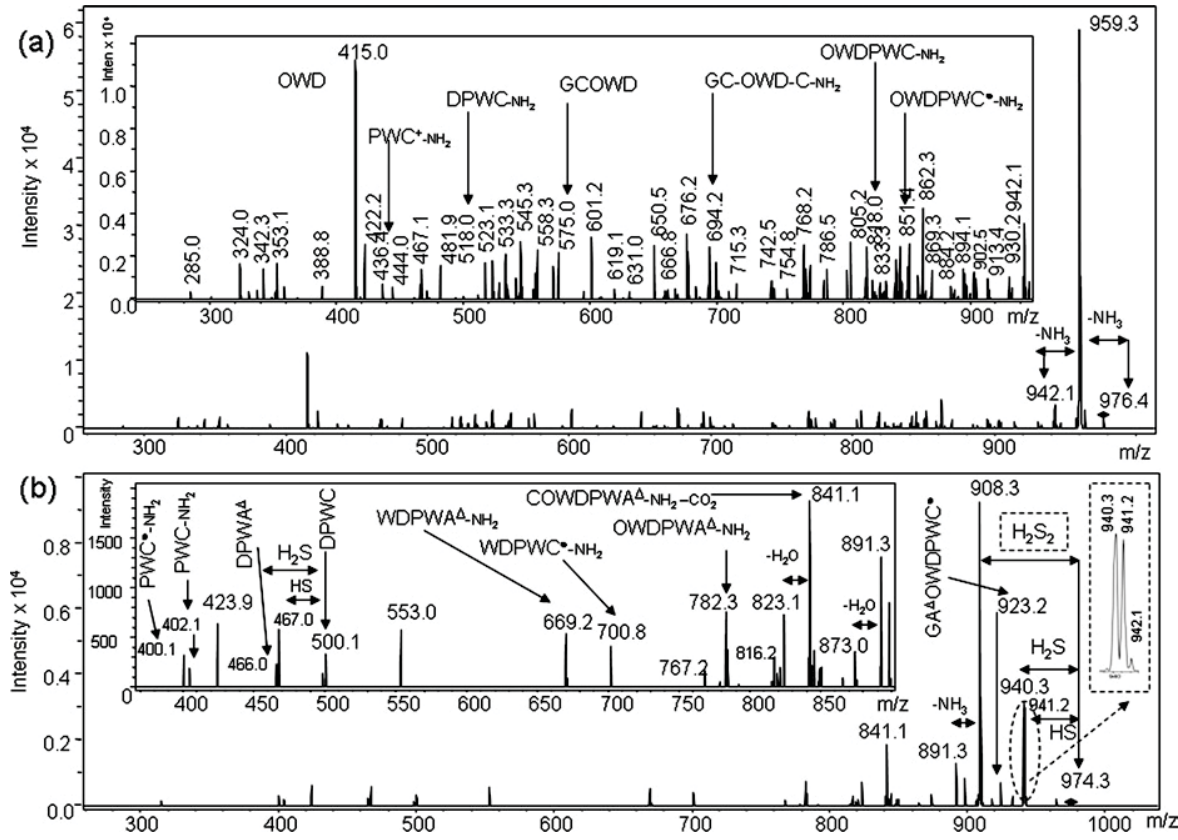

Figure 5. (a) LC-ESI-MS/MS spectrum of the contryphan Am 975 in positive ion mode. O (hydroxyproline): $113 \mathrm{Da}, \mathrm{C}^{*}$ (cysteine thioaldehyde): $101 \mathrm{Da}$. (b) LC-ESI-MS/MS spectrum of Am 975 in negative ion mode. $\mathrm{O}$ (hydroxyproline): $113 \mathrm{Da}, \mathrm{A}^{\Delta}$ (dehydroalanine): $69 \mathrm{Da}, \mathrm{C}^{-}$(cysteine thioaldehyde): $101 \mathrm{Da}$.

vations of two species for the persulfide suggest that scrambling does occur at the $\mathrm{C}^{\alpha}$ position in the gasphase anion. This may be anticipated in view of the significantly greater acidity of the $\mathrm{C}^{\alpha} \mathrm{H}$ group resulting in mobility of labile hydrogen resulting in HD scrambling. Further, the product ions at $\mathrm{m} / \mathrm{z} 276.3$ and $277.3 \mathrm{can}$ be assigned to species derived by the neutral loss of partially deuterated $\mathrm{H}_{2} \mathrm{~S}$ and $\mathrm{H}_{2} \mathrm{~S}_{2}$. Gas-phase scrambling of labile hydrogens (deuterium) [26, 27] precludes a more definitive assignment for the origin of these product ions.

Relatively few studies describe the fragmentation pattern of negative ions derived from disulfide pep- tides. In principle, backbone cleavages can arise from precursor ions bearing the negative ion at the amide nitrogen. Proton transfer can result in mobility of the negative charge along the peptide backbone. Figure $5 b$ provides an assignment of several of the product ions, which are readily detected, albeit at the low intensities.

These results established that negative ion fragmentation of intact peptide disulfides may provide important structural information. Scheme 4 schematically summarizes the anticipated cleavage products that can arise by fragmentation of a disulfide bridge. The observation of characteristic neutral loss of $\mathrm{H}_{2} \mathrm{~S}_{2}$ and $\mathrm{H}_{2} \mathrm{~S}$

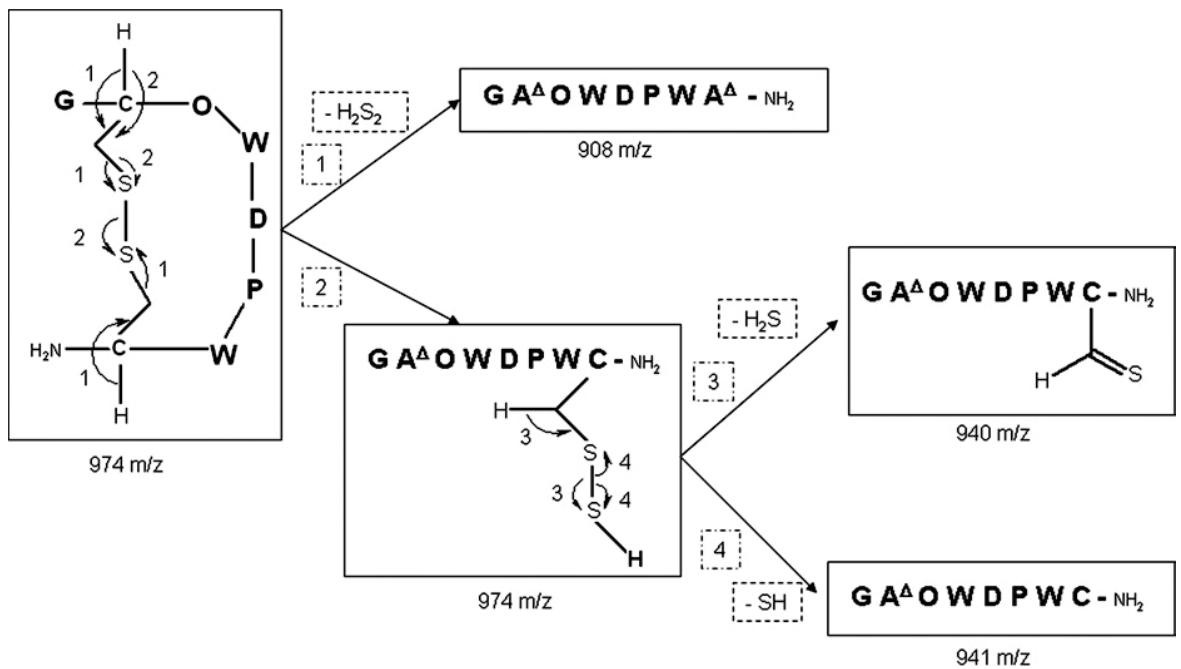

Scheme 3. Fragmentation modes at a disulfide bridge in contryphan Am 975. A ${ }^{\Delta}$ (dehydroalanine): $69 \mathrm{Da}, \mathrm{C}^{\cdot}$ (cysteine thioaldehyde): $101 \mathrm{Da}$. 


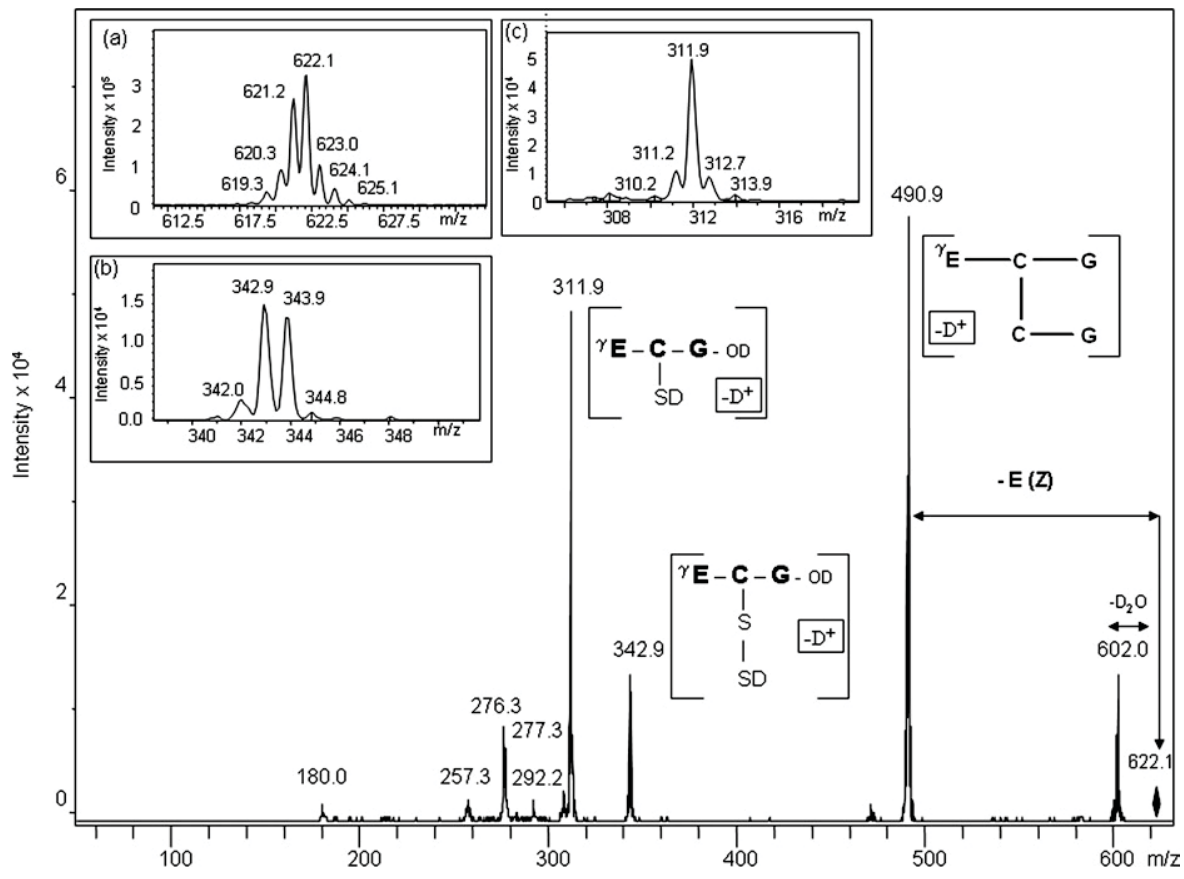

Figure 6. ESI-MS/MS of deuterated oxidized glutathione $\left(m / z\right.$ 622.1) in $\mathrm{D}_{2} \mathrm{O}$ containing $1 \mathrm{mM}$ deuterated ammonium acetate in negative ion mode. Inset shows expansion of peak at $\mathrm{m} / \mathrm{z}$ (a) 622.1 , (b) 342.9 , (c) 311.9 .

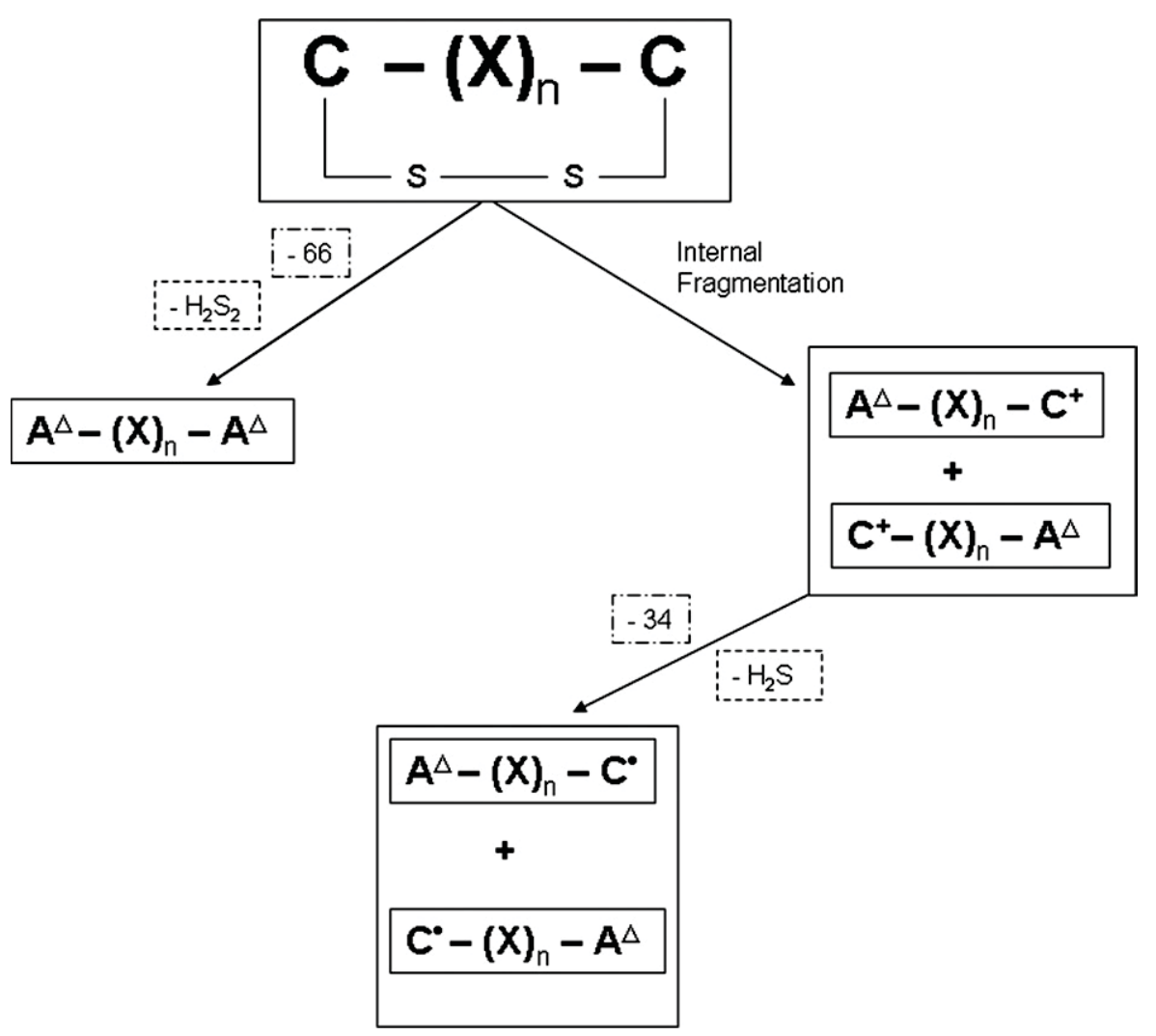

Scheme 4. General summary of product ions obtained following cleavage at a disulfide bridge in a cyclic system. $\mathrm{A}^{\Delta}$ (dehydroalanine): $69 \mathrm{Da}, \mathrm{C}^{\cdot}$ (cysteine thioaldehyde): $101 \mathrm{Da}, \mathrm{C}^{+}$: Cys-S-S-H (persulfide) $135 \mathrm{Da}, \mathrm{C}$ (cysteine): $103 \mathrm{Da}$. 
followed by assignment of the observed product ions can provide important information about the position of the linked Cys residues.

\section{Conclusions}

The fragmentation of peptide disulfides under mass spectrometric conditions follows distinct pathways when positive and negative ions are subjected to collision induced dissociation. Initial cleavage of the disulfide bond is predominant in the case of negative ions. Valuable sequence information can, in principle, be extracted by mass spectrometric fragmentation of intact peptide disulfides. Further development of this approach may facilitate the generation of sequence information, without resorting to the prior reduction and alkylation of disulfide bonds. The possibility of establishing disulfide connectivity by interpretation of mass spectra of peptides containing multiple disulfide bonds, under both positive and negative conditions, remains to be explored.

\section{Acknowledgments}

The authors are grateful to Professor K. S. Krishnan and to the past and present members of the conotoxin group for crude Conus venom samples. They thank Y. K. Subramanya Prakash for helping them with the ESI mass spectrometer. This research was supported by a grant from the Department of Biotechnology (DBT), Government of India. The mass spectrometer facility is supported by a proteomics program grant from DBT.

\section{References}

1. Krishnamurthy, T.; Prabhakaran, M.; Long, S. R. Mass Spectrometric Investigations on Conus Peptides. Toxicon 1996, 34, 1345-1359.

2. Yen, T. Y.; Yan, H.; Macher, B. A. Characterizing Closely Spaced Complex Disulfide Bond Patterns in Peptides and Proteins by Liquid Chromatography/Electrospray Ionization Tandem Mass Spectrometry. J. Mass Spectrom. 2002, 37, 15-30.

3. Jakubowski, J. A.; Keays, D. A.; Kelley, W. P.; Sandall, D. W.; Bingham, J. P.; Livett, B. G.; Gayler, K. R.; Sweedler, J. V. Determining Sequences and Post-Translational Modifications of Novel Conotoxins in Conus victoriae using cDNA Sequencing and Mass Spectrometry. J. Mass Spectrom. 2004, 39, 548-557.

4. Sabareesh, V.; Gowd, K. H.; Ramasamy, P.; Sudarslal, S.; Krishnan, K. S.; Sikdar, S. K.; Balaram, P. Characterization of Contryphans from Conus loroisii and Conus amadis that Target Calcium Channels. Peptides 2006, $27,2647-2654$.

5. Keough, T.; Youngquist, R. S.; Lacey, M. P. Sulfonic Acid Derivatives for Peptide Sequencing by MALDI MS. Anal. Chem. 2003, 75, 156A-165A.

6. Ewing, N. P.; Cassady, C. J. Dissociation of Multiply Charged Negative Ions for Hirudin (54-65), Fibrinopeptide B, and Insulin A (oxidized). J. Am. Soc. Mass Spectrom. 2001, 12, 105-116.

7. Gunawardena, H. P.; O'Hair, R. A.; McLuckey, S. A.; Selective Disulfide. Bond Cleavage in Gold (I) Cationized Polypeptide Ions Formed via Gas-Phase Ion/Ion Cation Switching. J. Proteome Res. 2006, 5, 2087-2092.
8. Zhang, M.; Kaltashov, I. A. Mapping of Protein Disulfide Bonds Using Negative Ion Fragmentation with a Broadband Precursor Selection. Anal. Chem. 2006, 78, 4820-4829.

9. Rubino, F. M.; Pitton, M.; Brambilla, G.; Colombi, A. A Study of the Glutathione Metaboloma Peptides by Energy-Resolved Mass Spectrometry as a Tool to Investigate into the Interference of Toxic Heavy Metals with their Metabolic Processes. J. Mass Spectrom. 2006, 41, 1578-1593.

10. Bilusich, D.; Bowie, J. H. Identification of Intermolecular Disulfide Linkages in Underivatized Peptides Using Negative Ion Electrospray Mass Spectrometry. A Joint Experimental and Theoretical Study. Rapid Commun. Mass Spectrom. 2007, 21, 619-628.

11. Lioe, H.; O'Hair, R. A. A Novel Salt Bridge Mechanism Highlights the Need for Nonmobile Proton Conditions to Promote Disulfide Bond Cleavage in Protonated Peptides Under Low-Energy Collisional Activation. J. Am. Soc. Mass Spectrom. 2007, 18, 1109-1123.

12. Lioe, H.; Duan, M.; O'Hair, R. A. Can Metal Ions be Used as Gas-Phase Disulfide Bond Cleavage Reagents? A Survey of Coinage Metal Complexes of Model Peptides Containing an Intermolecular Disulfide Bond. Rapid Commun. Mass Spectrom. 2007, 21, 2727-2733.

13. Jai-nhuknan, J.; Cassady, C. J. Negative Ion Matrix-Assisted Laser Desorption/Ionization Time-of-Flight Post-Source Decay Calibration by Using Fibrinopeptide B. J. Am. Soc. Mass Spectrom. 1998, 9, 540-544.

14. Jai-nhuknan, J.; Cassady, C. J. Negative Ion Postsource Decay Time-ofFlight Mass Spectrometry of Peptides Containing Acidic Amino Acid Residues. Anal. Chem. 1998, 70, 5122-5128.

15. Brinkworth, C. S.; Bowie, J. H., Bilusich, D.; Tyler, M. J. The Rothein Peptides from the Skin Secretion of Roth's Tree Frog Litoria rothii. Sequence Determination Using Positive and Negative Ion Electrospray Mass Spectrometry. Rapid Commun. Mass Spectrom. 2005, 19, 2716-2724.

16. Bilusich, D.; Brinkworth, C. S.; McAnoy, A. M.; Bowie, J. H. The Fragmentations of $[\mathrm{M}-\mathrm{H}]^{-}$Anions Derived from Underivatized Peptides. The Side-Chain Loss of $\mathrm{H}_{2} \mathrm{~S}$ from Cys. A Joint Experimental and Theoretical Study. Rapid Commun. Mass Spectrom. 2003, 17, 2488 2494.

17. Bilusich, D.; Brinkworth, C. S.; Bowie, J. H. Negative Ion Mass Spectra of Cys-Containing Peptides. The Characteristic Cys $\gamma$ Backbone Cleavage: A Joint Experimental and Theoretical Study. Rapid Commun. Mass Spectrom. 2004, 18, 544-552.

18. Bilusich, D.; Maselli, V. M.; Brinkworth, C. S.; Samguina, T.; Lebedev, A. T.; Bowie, J. H. Direct Identification of Intramolecular Disulfide Links in Peptides Using Negative Ion Electrospray Mass Spectra of Underivatized Peptides. A Joint Experimental and Theoretical Study. Rapid Commun. Mass Spectrom. 2005, 19, 3063-3074.

19. Thakur, S., S.; Balaram, P. Rapid Mass Spectral Identification of Contryphans Detection of Characteristic Peptide Ions by Fragmentation of Intact Disulfide Bonded Peptides in Crude Venom. Rapid Commun. Mass Spectrom. 2007, 21, 3420-3426.

20. Terlau, H.; Olivera, B. M. Conus Venoms: A Rich Source of Novel Ion Channel-Targeted Peptides. Physiol. Rev. 2004, 84, 41-68.

21. Mák, M.; Mezö, G.; Skribanek, Z.; Hudecz, F. Stability of Asp-Pro Bond under High and Low Energy Collision Induced Dissociation Conditions in the Immunodominant Epitope Region of Herpes simplex Virion Glycoprotein D. Rapid Commun. Mass Spectrom. 1998, 12, 837-842.

22. Skribanek, Z.; Mezo, G.; Mák, M.; Hudecz, F. Mass Spectrometric and Chemical Stability of the Asp-Pro Bond in Herpes simplex Virus Epitope Peptides Compared with X-Pro Bonds of Related Sequences. J. Pept. Sci. 2002, 8, 398-406

23. Nashef, A. S.; Osuga, D. T.; Lee, H. S.; Ahmed, A. I.; Whitaker, J. R.; Feeney, R. E. Effects of Alkali on Proteins. Disulfides and Their Products. J. Agric. Food Chem. 1977, 25, 245-251.

24. Florence, T. M. Degradation of Protein Disulphide Bonds in Dilute Alkali. Biochem. J. 1980, 189, 507-520.

25. Jones, A. J.; Helmerhorst, E.; Stokes, G. B. The Formation of Dehydroalanine Residues in Alkali-Treated Insulin and Oxidized Glutathione. A Nuclear-Magnetic-Resonance Study. Biochem. J. 1983, 211, 499-502.

26. Rand, K. D.; Jørgensen, T. J. Development of a Peptide Probe for the Occurrence of Hydrogen $\left({ }^{1} \mathrm{H} /{ }^{2} \mathrm{H}\right)$ Scrambling upon Gas-Phase Fragmentation. Anal. Chem. 2007, 79, 8686-8693.

27. Jørgensen, T. J.; Gårdsvoll, H.; Ploug, M.; Roepstorff, P. Intramolecular Migration of Amide Hydrogens in Protonated Peptides Upon Collisional Activation. J. Am. Chem. Soc. 2005, 127, 2785-2793. 